\title{
A Highly Selective Fluorescent Chemosensor for $\mathrm{Al}^{3+}$ Based on 2,2':6',2'-Terpyridine with a Salicylal Schiff Base
}

\author{
Jiacheng Xu, ${ }^{a}$ Hui Li, ${ }^{\oplus *, a}$ Liangwei Li, ${ }^{a}$ Jianzhi Wang, ${ }^{a}$ Feng Wang ${ }^{a}$ and Luying He ${ }^{a}$ \\ ${ }^{a}$ Key Laboratory for Green Chemical Process of Ministry of Education, School of Chemical \\ Engineering and Pharmacy, Wuhan Institute of Technology, 430205 Wuhan, P.R. China
}

Two 2,2':6',2"'-terpyridine-based Schiff bases (TPySSB and TPySB) have been synthesized. The TPySSB shows remarkable selective 'off-on' fluorescence for $\mathrm{Al}^{3+}$ in combination with photoinduced electron transfer (PET) mechanism and $\mathrm{C}=\mathrm{N}$ isomerization mechanism. Chemosensor TPySSB binds $\mathrm{Al}^{3+}$ in a 1:2 ratio with an association constant $6.8 \times 10^{5}$ (correlation coefficient $\left(\mathrm{R}^{2}\right)=0.98$ ) and this $1: 2$ stoichiometric model is established on Job's plot and ${ }^{1} \mathrm{H}$ nuclear magnetic resonance (NMR). Comparing TPySSB and TPySB, it is of great importance the existence of oxygen atom of hydroxyl group in salicylidene due to its strong binding abilities of both phenol and $\mathrm{C}=\mathrm{N}$ structure to the $\mathrm{Al}^{3+}$.

Keywords: 2,2':6',2”-terpyridine, salicylidene Schiff bases, fluorescence sensor, $\mathrm{Al}^{3+}$

\section{Introduction}

$\mathrm{Al}^{3+}$ ions exist in natural waters and most plants, which can enter the human body through food and water. ${ }^{1}$ Since $\mathrm{Al}^{3+}$ is closely related to human health, much attention have been paid to developing new high selectivity and sensitivity fluorescent chemosensors to detect $\mathrm{Al}^{3+}$. ${ }^{2}$ At present, fluorescent chemosensors have been widely used to detect different metal ions because of their high sensitivity, selectivity and fast response time. ${ }^{3}$ Typically, metal ion chemosensors are composed of a metal binding unit and signaling unit, which enable the fluorescent chemosensors to coordinate with metal ions. Later on, fluorescent sensors based on a large number of metal binding units with different structures, including pyrazoline, ${ }^{4}$ peptide, ${ }^{5}$ salicylimine,${ }^{6}$ tetrazole, ${ }^{7}$ triazole $,{ }^{8} 4,5$-diazafluorene ${ }^{9}$ and $2,2^{\prime}: 6^{\prime}, 2^{\prime \prime}$-terpyridine (TPy ${ }^{10}$ have been developed. Among these receptors, $2,2^{\prime}: 6^{\prime}, 2^{\prime \prime}$-terpyridine moiety is an ideal model for the construction of fluorescence sensors because of its excellent coordination ability with various metal ions. ${ }^{11}$ Indeed, it has become one of the most important chemical sensors in supramolecular chemistry. There are reports ${ }^{12}$ about the detection of anion and cation by $2,2^{\prime}: 6^{\prime}, 2$ '-terpyridine based fluorescent chemosensor. However, there is still no report of a sensor that can detect $\mathrm{Al}^{3+}$ by $2,2^{\prime}: 6^{\prime}, 2^{\prime \prime}$-terpyridine derivatives. Therefore, the

*e-mail: sodium2008@wit.edu.cn design and preparation of 2,2':6',2"'-terpyridine based fluorescent chemosensors are necessary for the construction and development of sensors for detecting $\mathrm{Al}^{3+}$ with high selectivity and sensitivity.

Salicylidene Schiff bases (SSB) have attracted increasing attention because they enable simple and inexpensive determinations of various metal ions. Over the past decades, it has been demonstrated that the presence of phenolic $\mathrm{OH}$ and azomethine $\mathrm{C}=\mathrm{N}$ double bond in Schiff base exhibit a strong affinity for transition metal ions. ${ }^{13}$ Due to the formation of the chelatogenic cycle (metal-oxygen-nitrogen chain), the intramolecular charge transfer (ICT) was highly improved between the $\pi$-conjugated rings. Mostly, these kinds of molecules display unique emission enhancement due to the inhibition of $\mathrm{C}=\mathrm{N}$ isomerization. ${ }^{14,15}$ Therefore, combination of $2,2^{\prime}: 6^{\prime}, 2^{\prime \prime}$-terpyridine and salicylidene Schiff base into a unique entity can produce an interesting system with very peculiar coordination properties. Herein, we report the design and synthesis of two new 2,2':6',2'-terpyridine Schiff base TPySSB and TPySB. Their binding properties toward metal ions have been investigated. The salicylidene Schiff base TPySSB could be used as a highly efficient fluorescence probes for $\mathrm{Al}^{3+}$ with high selectivity. As being fluorescence chemosensor, TPySSB with phenolic $\mathrm{OH}$ group shows better $\mathrm{Al}^{3+}$ sensing properties than TPySB due to the formation of terpyridine- $\mathrm{Al}^{3+}$ complex and the inhibition of $\mathrm{C}=\mathrm{N}$ isomerization. 


\section{Results and Discussion}

\section{Synthesis and characterization}

Synthesis procedure of the Schiff base derivatives TPySSB and TPySB is shown in Scheme 1. Compound TPySSB (or TPySB) was synthesized through condensation reaction between 4'-amine-2,2':6',2"'-terpyridines and salicylaldehyde (or benzaldehyde) in refluxing methanol. The products obtained in high yield were characterized by Fourier transform infrared (FTIR), mass spectroscopy (MS), ${ }^{1} \mathrm{H}$ and ${ }^{13} \mathrm{C}$ nuclear magnetic resonance (NMR). The FTIR spectra (Figure S1, Supplementary Information (SI) section) of compounds TPySSB and TPySB display the characteristic peaks of $\mathrm{C}=\mathrm{N}$ vibration at 1622 and $1620 \mathrm{~cm}^{-1}$, respectively. A broad band centered at $3428 \mathrm{~cm}^{-1}$ is detected in TPySSB absorption spectra, which is attributed to $\mathrm{O}-\mathrm{H}$ stretching vibration. The ${ }^{1} \mathrm{H}$ NMR spectra of TPySSB and TPySB in acetone- $d_{6}$ fit well with the expected molecular structure. The chemical shift of $-\mathrm{CH}=\mathrm{N}$ proton in the spectrum of TPySB is about $8.62 \mathrm{ppm}$ (Figure S4, SI section). The chemical shift of $-\mathrm{CH}=\mathrm{N}$ proton shifted downfield about 8.96 ppm comparing with that of TPySSB (Figure S2, SI section). ${ }^{16}$ A singlet at $13.18 \mathrm{ppm}$ corresponding to $-\mathrm{OH}$ is displayed in the spectrum of TPySSB, confirming the existence of an intermolecular hydrogen bonding of the phenol OH. ${ }^{17}$

Recognition experiment of Schiff base (TPySSB and TPySB) in the presence of various metal ions

To compare the fluorescence response behavior of Schiff base (TPySSB and TPySB) in the presence of multiple types of metal ions, the recognition experiment of Schiff base (TPySSB and TPySB) was performed in ethanol at room temperature. As shown in Figure 1a, TPySSB with (or without) other cations displayed a
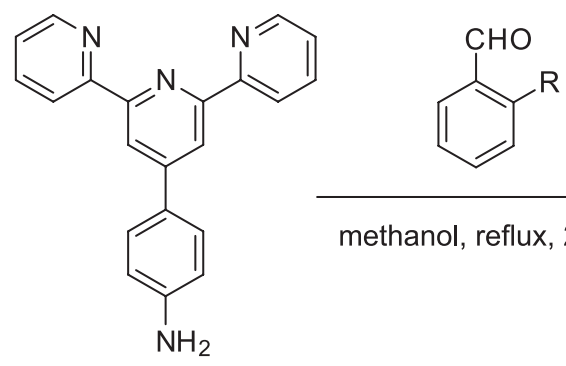

methanol, reflux, $24 \mathrm{~h}$

$$
\text { . }
$$

weak single fluorescence emission band at $528 \mathrm{~nm}$ when it was excited at $265 \mathrm{~nm}$ except for $\mathrm{Al}^{3+}$ and $\mathrm{Pb}^{2+}$. Upon the addition of $\mathrm{Al}^{3+}$, an obvious fluorescence enhancement at $516 \mathrm{~nm}$ on TPySSB is achieved due to the inhibited photo-induced electron transfer $(\mathrm{PET})^{18}$ with the formation of TPySSB-Al ${ }^{3+}$ and the inhibition of $\mathrm{C}=\mathrm{N}$ isomerization process. ${ }^{14,15}$ The Stokes shifts $(12 \mathrm{~nm})$ of TPySSB and TPySSB-Al ${ }^{3+}$ complex are attributable to their stronger intramolecular charge transfer. ${ }^{19}$ The selectivity of TPySSB has been plotted as a bar graph in Figure $1 b$. It can be found that $\mathrm{Al}^{3+}$ produces the most conspicuous fluorescence enhancement (51-fold at $516 \mathrm{~nm}$ ), although $\mathrm{Pb}^{2+}$ can also induce about 5-fold increase, which indicated the Schiff base TPySSB as a fluorescent sensor for $\mathrm{Al}^{3+}$ is highly selective. To further evaluate the proposed complexation model and study the role of oxygen atom of phenol group in salicylidene during its interactions with metal cations, compound TPySB (Scheme 1) was also synthesized. It possesses similar structure of TPySSB except for lack of phenol group. TPySB alone displayed two weak fluorescence emission bands at 329 and $410 \mathrm{~nm}$ after being excited at $258 \mathrm{~nm}$. However, upon addition of various metal ions, significant changes in fluorescence intensity appears at $329 \mathrm{~nm}$ (for $\mathrm{Ag}^{+}, \mathrm{Cu}^{2+}, \mathrm{Fe}^{3+}, \mathrm{Fe}^{2+}, \mathrm{Cr}^{2+}$ and $\mathrm{Al}^{3+}$ ) or $410 \mathrm{~nm}$ (for $\mathrm{Co}^{2+}, \mathrm{Mn}^{2+}, \mathrm{Mg}^{2+}, \mathrm{Pb}^{2+}, \mathrm{Sr}^{2+}$ and $\mathrm{Zn}^{2+}$ ) except for alkali metals such as $\mathrm{Na}^{+}, \mathrm{K}^{+}$and $\mathrm{Li}^{+}$(Figure 1c), indicating the enhancement effect of fluorescence accompanied by formation of metal-ligand complexes. These results prove that terpyridine ligand have strong ability to coordinate with metal ions. By analyzing the structure of TPySSB and TPySB, we can draw the following deductions: $(i)$ the chelation of nitrogen atom of 2,2':6',2"'-terpyridine with $\mathrm{Al}^{3+}$ initiates the PET process efficiently; (ii) the interaction between the oxygen atom of phenol unit present in salicylidene moiety and $\mathrm{Al}^{3+}$ can lead to the inhibition of $\mathrm{C}=\mathrm{N}$ isomerization ${ }^{14}$ due to strong binding abilities of both phenol and $\mathrm{C}=\mathrm{N}$ structure

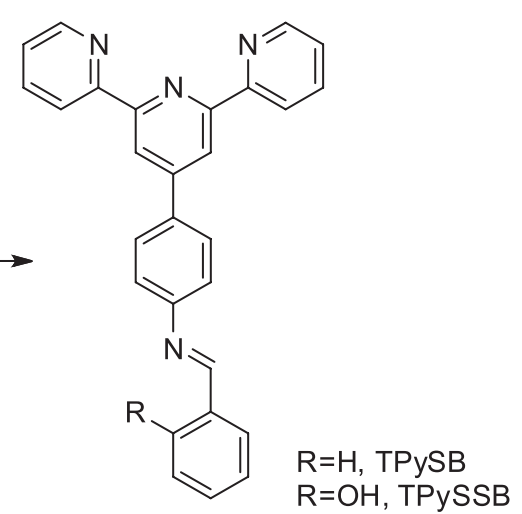

Scheme 1. Synthesis of TPySSB and TPySB. 
to the $\mathrm{Al}^{3+},{ }^{20}$ which can be used to explain the reason for the excellent performance of the TPySSB, which is designed by combining 2,2':6',2"-terpyridine unit and salicylidene unit. The effect of $\mathrm{pH}$ on the fluorescence properties of the system is shown in Figure S5 (SI section). It is obvious that the biggest emission enhancement upon addition of $\mathrm{Al}^{3+}$ could be obtained when $\mathrm{pH}$ was adjusted to 9.0. Furthermore, under this condition, the fluorescent intensity at $516 \mathrm{~nm}$ is observed to increase markedly over time (Figure S6, SI section), indicating that probe TPySSB takes a long reaction time to realize detection of $\mathrm{Al}^{3+}$. The reversibility of sensor TPySSB $\left(1 \times 10^{-5} \mathrm{~mol} \mathrm{~L}^{-1}\right)$ has been evaluated by the titration of $\mathrm{Al}^{3+}\left(1 \times 10^{-4} \mathrm{~mol} \mathrm{~L}^{-1}\right)$ and ethylenediamine tetraacetic acid (EDTA, $1 \times 10^{-4} \mathrm{~mol} \mathrm{~L}^{-1}$ ) (Figure S7, SI section). The whole process was repeated three times, by alternating $\mathrm{Al}^{3+}\left(1 \times 10^{-4} \mathrm{~mol} \mathrm{~L}^{-1}\right)$ and EDTA $\left(1 \times 10^{-4} \mathrm{~mol} \mathrm{~L}^{-1}\right)$. The emission of the TPySSB-Al ${ }^{3+}$ could be basically recovered, though small drifts for both turn-off and turnon fluorescent signals were detected.
Selectivity study of Schiff base (TPySSB and TPySB) for $\mathrm{Al}^{3+}$ over competitive metal ions

The selectivity of chemosensor for $\mathrm{Al}^{3+}$ in comparison to other competing metal ions is indispensable in evaluating its sensing performance. To further confirm the high selectivity of chemosensor TPySSB for $\mathrm{Al}^{3+}$, competitive selectivity tests of chemosensor TPySSB toward various metal ions were performed in ethanol. In a single metal system (black bars, Figure 2), the concentrations of metal ions were set to be $100 \mu \mathrm{M}$ towards TPySSB. However, for the dual-metal (red bars, Figure 2) studies, aqueous solutions of $\mathrm{Al}^{3+}(100 \mu \mathrm{M})$ and the other metal ions $(100 \mu \mathrm{M})$ were combined. Relatively low interferences were observed for the detection of $\mathrm{Al}^{3+}$ in the presence of other metal ions, except for $\mathrm{Fe}^{3+}$ (Figure 2). Comparing competitive selectivity experiments of chemosensor TPySSB, high interferences are demonstrated on chemosensor TPySB in the existence of other metal ions, except for alkali metals such as $\mathrm{Na}^{+}$,
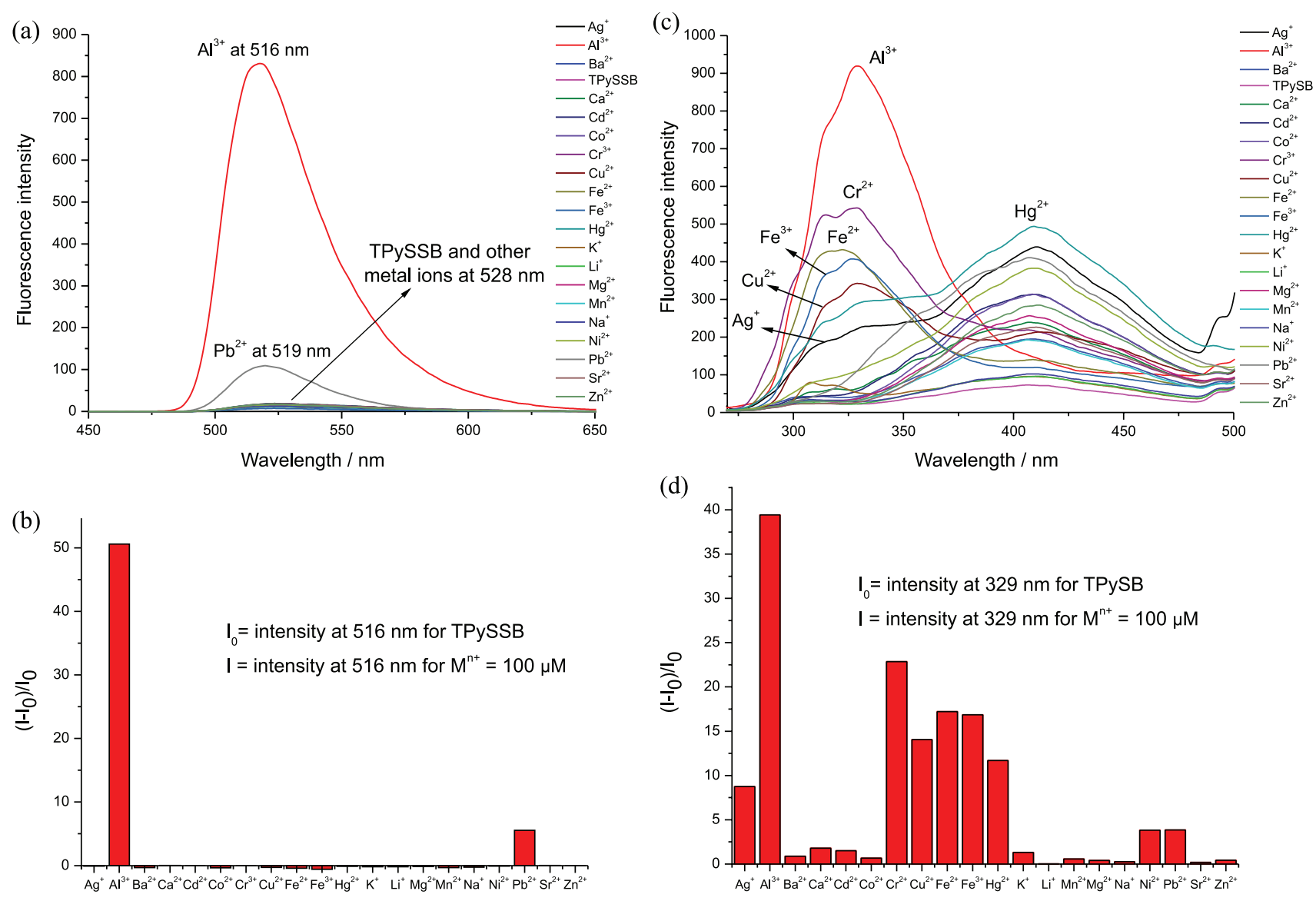

Figure 1. (a) Fluorescence spectra of the TPySSB $\left(1 \times 10^{-5} \mathrm{~mol} \mathrm{~L}^{-1}\right)$ in the presence of 10 equiv. of various metal ions in ethanol. Excitation wavelength: $265 \mathrm{~nm}$; (b) fluorescence emission response profiles for TPySSB $\left(1 \times 10^{-5} \mathrm{~mol} \mathrm{~L}^{-1}\right)$ by adding various metal ions $\left(1 \times 10^{-4} \mathrm{~mol} \mathrm{~L}^{-1}\right)$ at $516 \mathrm{~nm}$ in ethanol; (c) fluorescence spectra of the TPySB $\left(1 \times 10^{-5} \mathrm{~mol} \mathrm{~L}^{-1}\right)$ in the presence of 10 equiv. of various metal ions in ethanol. Excitation wavelength: $258 \mathrm{~nm}$; (d) fluorescence emission response profiles for TPySB $\left(1 \times 10^{-5} \mathrm{~mol} \mathrm{~L}^{-1}\right)$ by adding various metal ions $\left(1 \times 10^{-4} \mathrm{~mol} \mathrm{~L}^{-1}\right)$ at $329 \mathrm{~nm}$ in ethanol. 
$\mathrm{K}^{+}$and $\mathrm{Li}^{+}$(Figure $\mathrm{S} 8$, SI section). The unique selectivity of TPySSB towards $\mathrm{Al}^{3+}$ could be attributed to the strong ability to coordinate with $\mathrm{Al}^{3+}$ of $2,2^{\prime}: 6^{\prime}, 2^{\prime \prime}$-terpyridine unit and salicylidene unit.

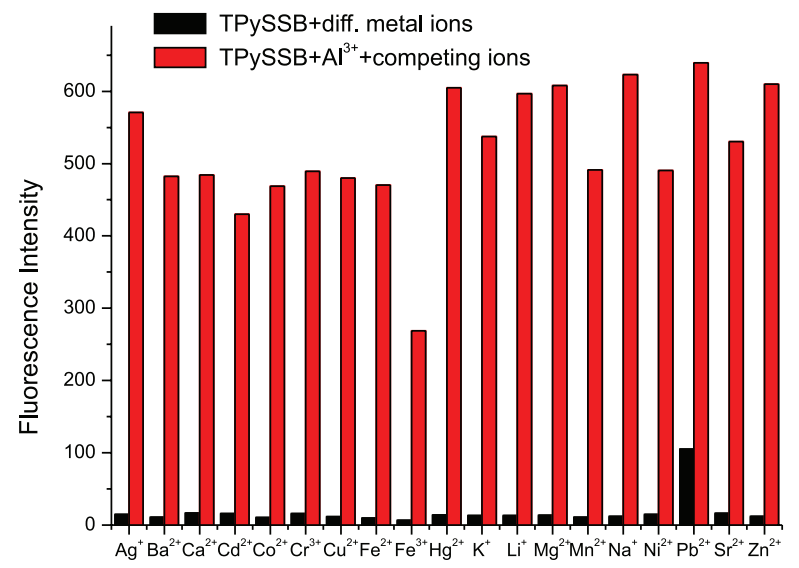

Figure 2. Fluorescence response of receptor TPySSB $\left(1 \times 10^{-5} \mathrm{~mol} \mathrm{~L}^{-1}\right)$. The black bar represents emission intensity after adding 10 equiv. selected metal ions in ethanol solution and red bar represents emission intensity after adding 10 equiv. of $\mathrm{Al}^{3+}$ ions in each of the above samples. Excitation wavelength: $265 \mathrm{~nm}$.

Fluorescence titration of Schiff base (TPySSB) in the presence of increasing concentration of $\mathrm{Al}^{3+}$

Fluorescence titration experiments were implemented to gain insight into the binding interaction between TPySSB with $\mathrm{Al}^{3+}$. Increasing the concentration of $\mathrm{Al}^{3+}$, it resulted in a very small $(8 \mathrm{~nm})$ blue-shift of the emission maxima with a 14-fold enhancement of the fluorescence intensity (Figure 3a). The calibration curve is linear from 30 to $90 \mu \mathrm{M}$ with a correlation coefficient of 0.990 (Figure 3b).

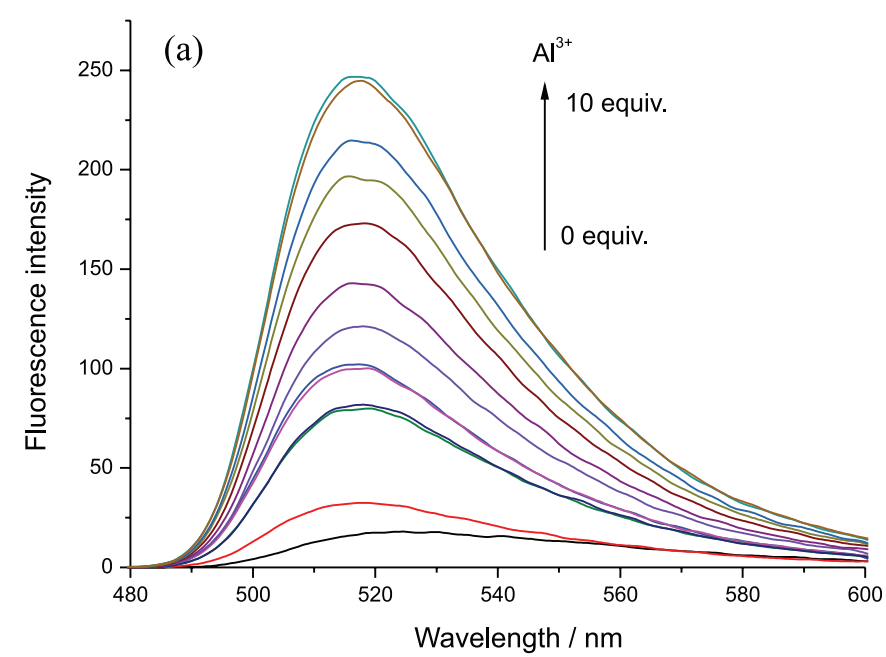

Ultraviolet-visible (UV-Vis) titration of Schiff base (TPySSB) in the presence of increasing concentration of $\mathrm{Al}^{3+}$

The chemosensor TPySSB toward various metal cations, $\mathrm{Ag}^{+}, \mathrm{Ba}^{2+}, \mathrm{Ca}^{2+}, \mathrm{Cd}^{2+}, \mathrm{Co}^{2+}, \mathrm{Cr}^{3+}, \mathrm{Cu}^{2+}, \mathrm{Fe}^{2+}, \mathrm{Fe}^{3+}$, $\mathrm{Hg}^{2+}, \mathrm{K}^{+}, \mathrm{Mn}^{2+}, \mathrm{Na}^{+}, \mathrm{Ni}^{2+}, \mathrm{Pb}^{2+}$ and $\mathrm{Zn}^{2+}$ are investigated by UV-Vis spectroscopy in ethanol. The absorption spectrum of chemosensor TPySSB displayed three absorbance peaks. The intense absorption bands in high energy region at 210 and $275 \mathrm{~nm}$ are attributed to the $\pi-\pi^{*}$ transitions of the terpyridine unit, ${ }^{21}$ while a broad band located between 300 and $400 \mathrm{~nm}$ could be ascribed to $\pi \rightarrow \pi^{*}$ transition of the $\mathrm{C}=\mathrm{N}$ group from salicylidene moiety. ${ }^{22}$ With the increasing concentration of $\mathrm{Al}^{3+}$, a $14 \mathrm{~nm}$ redshift for the $210 \mathrm{~nm}$ band appears on the UV-Vis spectrum, which is the reflectance of inhibition effect of $\mathrm{Al}^{3+}$ on the $\mathrm{C}=\mathrm{N}$ isomerization. The complex can change the $\mathrm{C}=\mathrm{N}$ isomerization molecular conformation dramatically, leading to a molecular coplanar structure. ${ }^{19}$ The absorption maximum at $350 \mathrm{~nm}$ decreased which was attributed to the form of TPySSB-Al ${ }^{3+}$ complex (Figure 4b). What is more, no significant absorption spectral change was observed for other cations under similar experimental conditions (Figure 4a).

\section{Job's plot measurements}

To further explore the binding mechanism, the binding stoichiometry of TPySSB with $\mathrm{Al}^{3+}$ was investigated via Job's plot of the fluorescence titrations of $\mathrm{Al}^{3+}$, and the total concentration of $\mathrm{Al}^{3+}$ and TPySSB was kept as $20 \mu \mathrm{M}$ as shown in Figure 5. The maximum absorption was achieved at the molar fraction of 0.7 , indicating a 1:2 stoichiometric

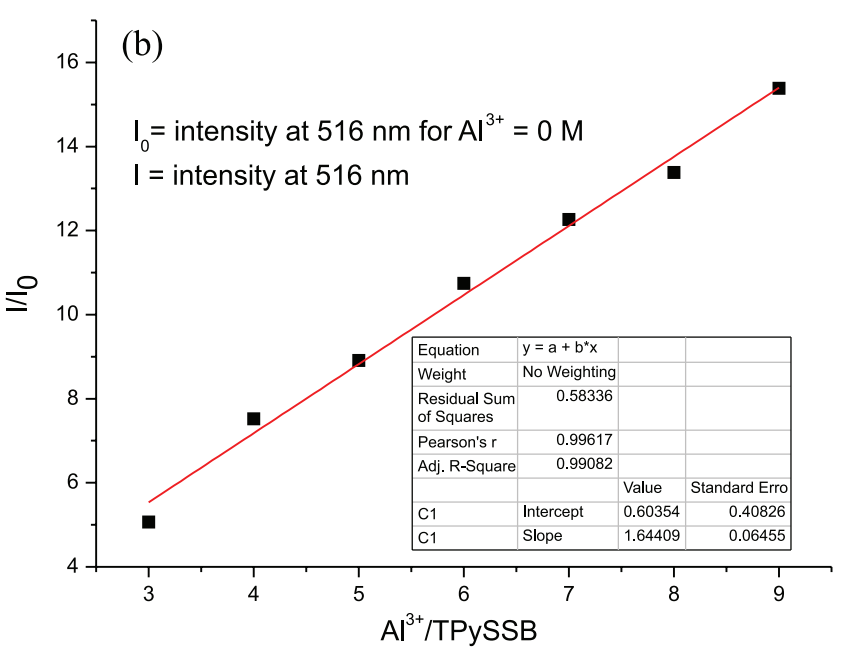

Figure 3. (a) Fluorescence emission spectra of receptor TPySSB $\left(1 \times 10^{-5} \mathrm{~mol} \mathrm{~L}^{-1}\right)$ in ethanol solution upon addition of increasing concentration of $\mathrm{Al}^{3+}$ (3-9 equiv.). Excitation wavelength: $265 \mathrm{~nm}$; (b) fluorescence intensity at $516 \mathrm{~nm}$ versus the number of equivalents of $\mathrm{Al}^{3+}$ added. 

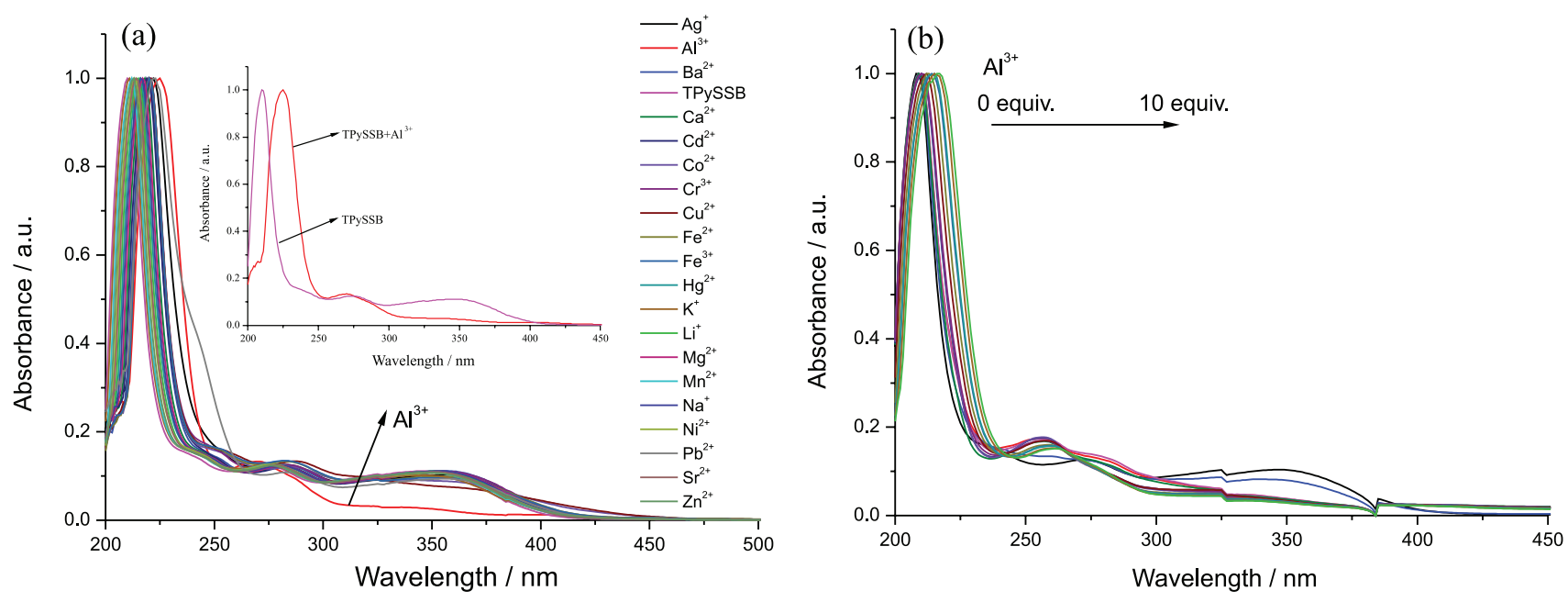

Figure 4. (a) UV-Vis spectra of the TPySSB $\left(1 \times 10^{-5} \mathrm{~mol} \mathrm{~L}^{-1}\right)$ in the presence of 10 equiv. of various metal ions in ethanol; (b) change in absorption spectra of TPySSB $\left(1 \times 10^{-5} \mathrm{~mol} \mathrm{~L}^{-1}\right)$ upon addition of increasing concentration of $\mathrm{Al}^{3+}$ (0-10 equiv.) in ethanol.

complexation between TPySSB and $\mathrm{Al}^{3+}$ for the newly formed complex. The binding stoichiometry of TPySB with $\mathrm{Al}^{3+}$ was also investigated and the results indicated a 1:1 stoichiometric complexation between TPySB and $\mathrm{Al}^{3+}$ (Figure S9, SI section). Therefore, the introduction of the phenolic $\mathrm{OH}$ into the $2,2^{\prime}: 6^{\prime}, 2^{\prime \prime}$-terpyridine-based Schiff base has led to new chemosensor with highly selective detection of $\mathrm{Al}^{3+}$.

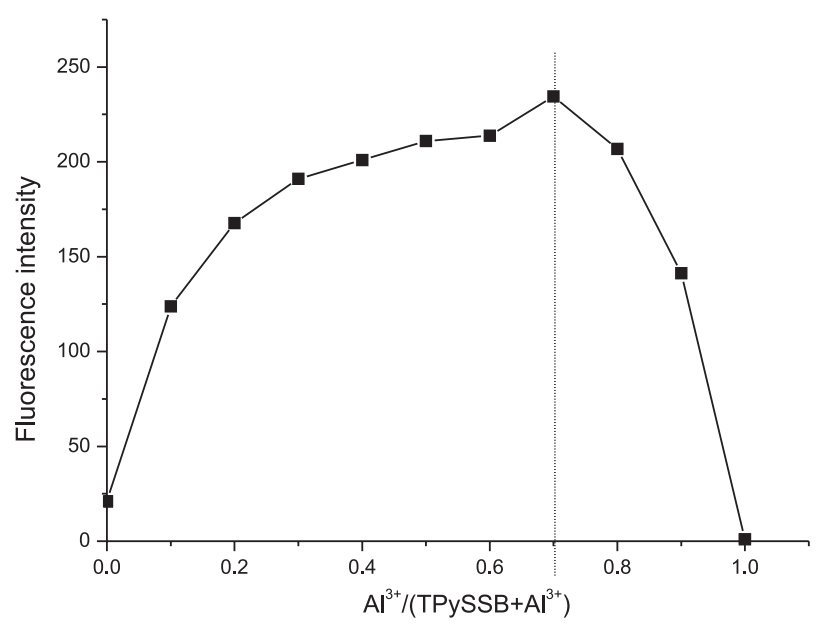

Figure 5. Job's plot for the complexation of TPySSB with $\mathrm{Al}^{3+}$ in ethanol. Total concentration of TPySSB and $\mathrm{Al}^{3+}$ is $20 \mu \mathrm{M}$.

\section{Determination of association constant and limit of detection}

Based on the fluorescence titration of TPySSB with $\mathrm{Al}^{3+}$, the association constant is determined to be $6.8 \times 10^{5} \mathrm{M}^{-1}$ (Figure 6) by a Benesi-Hildebrand equation. The binding constants of the inclusion complex were obtained from the fluorescence titration data. According to the BenesiHildebrand method, the equation for a 1:2 host:guest complex is given below: $\log \frac{\mathrm{I}-\mathrm{I}_{\min }}{\mathrm{I}_{\max }-\mathrm{I}}=\log [\mathrm{M}]^{2}-\log \mathrm{K}_{\mathrm{d}}$

where $K_{d}$ is the dissociation constant and $M$ represents concentrations of metals. $\mathrm{I}_{\min }$, I and $\mathrm{I}_{\max }$ are the different fluorescence emission intensity at $\lambda_{\max }=516 \mathrm{~nm}$ at initial, interval and final state of the complex, respectively. Association constant $\mathrm{K}_{\mathrm{a}}$ were evaluated graphically by the plot of $\log \left[\left(\mathrm{I}-\mathrm{I}_{\min }\right) /\left(\mathrm{I}_{\max }-\mathrm{I}\right)\right]$ versus $\log \left[\left(\mathrm{Al}^{3+}\right)^{2}\right]$. Figure $3 \mathrm{~b}$ also further confirms the good linearity between enhancing efficiency $\left(\mathrm{I} / \mathrm{I}_{0}\right)$ at $516 \mathrm{~nm}$ and concentrations of $\mathrm{Al}^{3+}$ in the range from 30 to $90 \mu \mathrm{M}$, indicating that sensor TPySSB can detect quantitatively relevant concentrations of $\mathrm{Al}^{3+}$. The limits of detection (LODs) were calculated through:

$\mathrm{LOD}=\frac{3 \sigma}{\mathrm{S}}$

where $\sigma$ is the standard deviation of the blank measurement, which is $0.4(n=11)$ here, and $S$ is the slope of the emission intensity $v s$. the concentration of aluminum ion curve. The LOD of $\mathrm{Al}^{3+}$ is $3.32 \times 10^{-7} \mathrm{~mol} \mathrm{~L}^{-1}$.

Effects of solvent on the sensing properties of Schiff base TPySSB towards $\mathrm{Al}^{3+}$

Optical sensing nature of chemosensors was dependent on the solvent nature, so the response of TPySSB towards $\mathrm{Al}^{3+}$ was also examined in different solvents such as ethanol, $N, N$-dimethylformamide (DMF), methanol, tetrahydrofuran (THF), 1,4-dioxane at maxima of emission intensity. From emission spectra of TPySSB and $\mathrm{Al}^{3+}$ at same concentrations in different solvents (Figure 7), the 


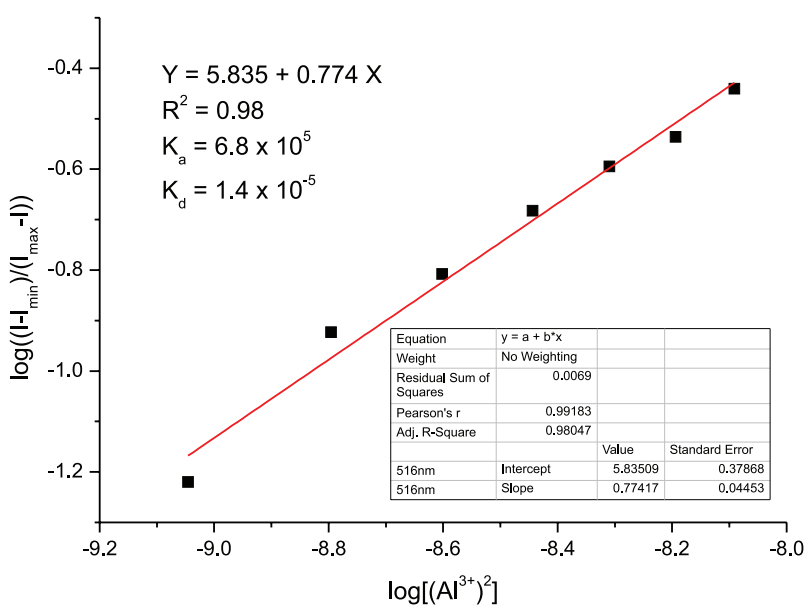

Figure 6. Hill plot of fluorescent probe (TPySSB-Al ${ }^{3+}$ ) at $\lambda_{\mathrm{em}}=516 \mathrm{~nm}$.

change of emission intensity has been studied. In ethanol, the solution of TPySSB and $\mathrm{Al}^{3+}$ have strong fluorescence whereas they show very weak fluorescence in other solvents such as the THF, 1,4-dioxane, DMF and methanol. Therefore, ethanol was chosen as solvent.

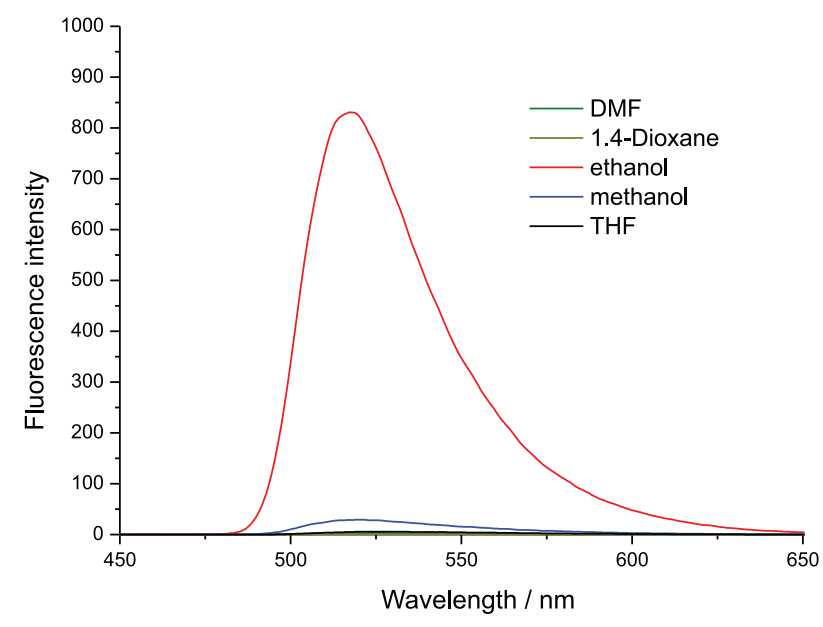

Figure 7. Fluorescence spectra of the TPySSB $(10 \mu \mathrm{M})$ in the presence of 10 equiv. of $\mathrm{Al}^{3+}$ in different solvents. Excitation wavelength: $265 \mathrm{~nm}$.

\section{Proposed binding mechanism}

In order to understand the structural information of $\mathrm{Al}^{3+}$ binding in TPySSB-Al ${ }^{3+}$ complex, the technique of FTIR spectrum is applied. For the free compound TPySSB, the characteristic infrared (IR) peak of the $\mathrm{C}=\mathrm{N}$ group of azomethine in Schiff base is detected at $1573 \mathrm{~cm}^{-1}$, while the typical IR peak of the $\mathrm{C}-\mathrm{O}$ group of salicylidene in Schiff base is located at $1188 \mathrm{~cm}^{-1}$. Upon addition of $\mathrm{Al}^{3+}$, the characteristic IR peak at 1573 and $1188 \mathrm{~cm}^{-1}$ disappeared, and new characteristic IR peak at 1703, 1523 and $1385 \mathrm{~cm}^{-1}$ appeared (Figure 8). This suggested that the phenolic $\mathrm{OH}$, the nitrogen atom in azomethine and the pyridine have participated in the coordination with
$\mathrm{Al}^{3+}$. The binding mode of TPySSB with $\mathrm{Al}^{3+}$ was also studied by analyzing electrospray ionization MS spectra. A characteristic peak at $\mathrm{m} / \mathrm{z}, 580.0779$, corresponding to $\left[\mathrm{TPySSB}+2 \mathrm{Al}^{3+}+\mathrm{NO}_{3}{ }^{-}+2 \mathrm{H}_{2} \mathrm{O}-\mathrm{H}^{+}\right]^{+},{ }^{23}$ is present in the positive-ion mass spectrum of TPySSB-Al ${ }^{3+}$ complex, confirming that the stoichiometry ratio between TPySSB and $\mathrm{Al}^{3+}$ is $1: 2$.

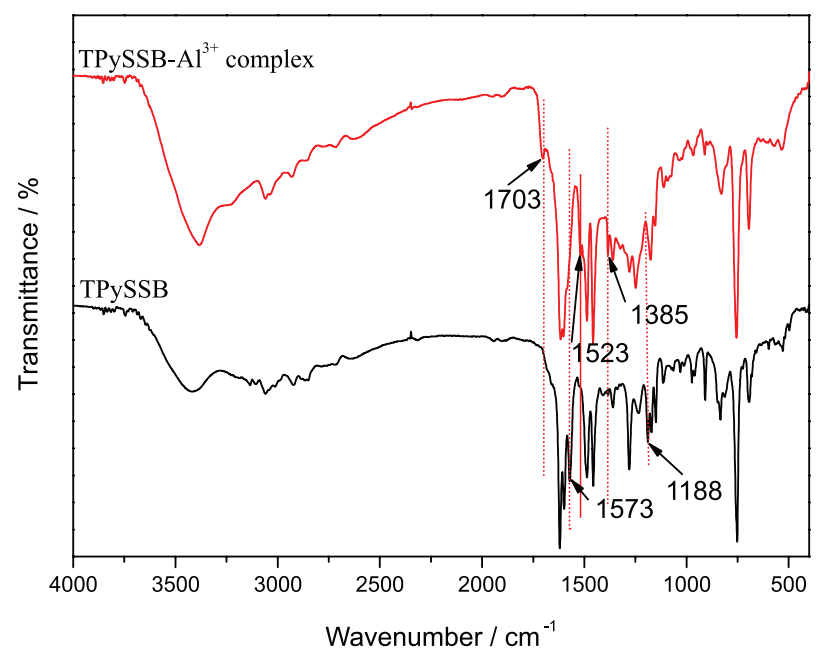

Figure 8. FTIR spectra (KBr) of chemosensor TPySSB and TPySSB-Al ${ }^{3+}$ complex.

Figure 9 shows the ${ }^{1} \mathrm{H}$ NMR spectra of single TPySSB and complex TPySSB-Al ${ }^{3+}$. The absence of the chemical shift corresponding to the proton in the phenolic hydroxyl and the azomethine- $\mathrm{H}$ further confirms the coordination of the phenolic hydroxy, nitrogen atom in azomethine and pyridine with $\mathrm{Al}^{3+}$. According to the above results, the proposed binding mode between TPySSB and $\mathrm{Al}^{3+}$ is inferred as follows, as shown in Figure 10. The effectiveness of TPySSB on the coordination of $\mathrm{Al}^{3+}$ is focused on its oxygen on phenolic group and nitrogen on the azomethine and pyridine. It is accepted generally that the chelating moiety of 2,2':6',2"-terpyridine and the chelating groups of $\mathrm{C}=\mathrm{N}$ and $-\mathrm{OH}$ are very closely associated with the metal cations, which is attributed to the synergistic effect of the inhibition of $\mathrm{C}=\mathrm{N}$ isomerization and photoinduced electron-transfer process between the terpyridine- $\mathrm{Al}^{3+}$ moiety and salicylidene moiety of the molecule. Therefore, for TPySSB, both the fluorescence enhancement and the high selectivity are focused on $\mathrm{Al}^{3+}$, which is over the other tested metal ions.

\section{Conclusions}

In summary, we have developed two new 2,2':6',2"'-terpyridines-derived Schiff base chemosensors (TPySSB and TPySB) for the highly selective determination 


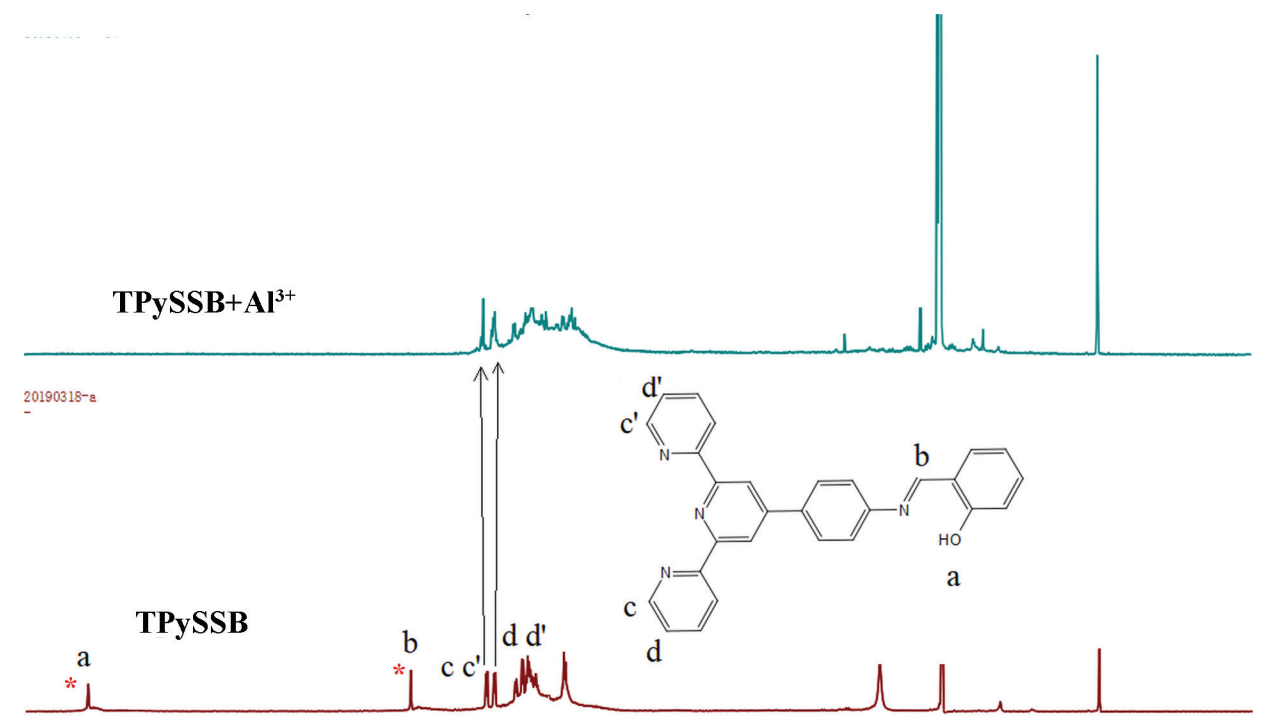

\begin{tabular}{lllllllllllllllll}
\hline 4 & 13 & 12 & 11 & 10 & 9 & 8 & 7 & $\begin{array}{c}6 \\
\mathrm{ppm}\end{array}$ & 5 & 4 & 3 & 2 & 1 & 0 & -1 & $-i$
\end{tabular}

Figure 9. ${ }^{1} \mathrm{H}$ NMR spectra (400 MHz, acetone- $d_{6}$ ) of TPySSB with 2.2 equiv. of $\mathrm{Al}^{3+}$ complex and TPySSB.

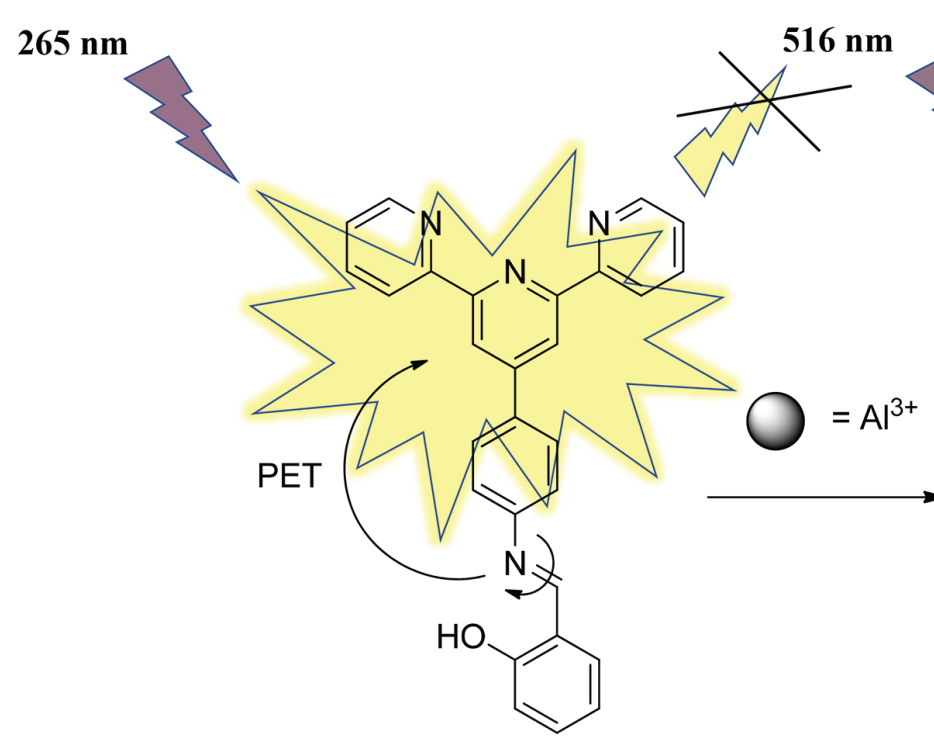

PET form $\mathrm{N}$ atom $\mathrm{C}=\mathrm{N}$ isomerization

Non-fluorescent
$265 \mathrm{~nm}$

$516 \mathrm{~nm}$

Figure 10. Proposed mechanism for the fluorescent sensing of TPySSB to $\mathrm{Al}^{3+}$.

of $\mathrm{Al}^{3+}$ in ethanol. The sensing property of TPySSB and TPySB was studied by UV-Vis, fluorescence, FTIR and ${ }^{1} \mathrm{H}$ NMR experiments. Upon addition of metal ions, the TPySSB shows remarkable 'off-on' fluorescence for $\mathrm{Al}^{3+}$. Moreover, it displayed excellent selectivity to $\mathrm{Al}^{3+}$ with a 1:2 binding mode which was proposed based on a Job's plot and confirmed by ${ }^{1} \mathrm{H}$ NMR analysis. Based on these results, we believe that combining $2,2^{\prime}: 6$ ',2'-terpyridine unit and salicylidene unit will offer an important guidance to the development of a highly selective chemosensor.

\section{Experimental}

Materials and instruments

4'-Amine-2,2':6',2'-terpyridines was synthesized 
by a method previously described in the literature. ${ }^{24}$ Salicylaldehyde and benzaldehyde were purchased from Innochem (Beijing, China) and used without further purification. All organic solvents were of analytical reagent grade. The metal ions were $\mathrm{NaCl}, \mathrm{KCl}, \mathrm{CaCl}_{2}, \mathrm{MgCl}_{2} \cdot 6 \mathrm{H}_{2} \mathrm{O}$, $\mathrm{NiCl}_{2} \cdot 6 \mathrm{H}_{2} \mathrm{O}, \mathrm{CuCl}_{2} \cdot 2 \mathrm{H}_{2} \mathrm{O}, \mathrm{ZnCl}_{2}, \mathrm{BaCl}_{2} \cdot 2 \mathrm{H}_{2} \mathrm{O}, \mathrm{HgCl}_{2}$, $\mathrm{CoCl}_{2} \cdot 6 \mathrm{H}_{2} \mathrm{O}, \mathrm{MnCl}_{2} \cdot 4 \mathrm{H}_{2} \mathrm{O}, \mathrm{FeCl}_{2} \cdot 4 \mathrm{H}_{2} \mathrm{O}, \mathrm{FeCl}_{3} \cdot 6 \mathrm{H}_{2} \mathrm{O}$, $\mathrm{CrCl}_{3} \cdot 6 \mathrm{H}_{2} \mathrm{O}, \mathrm{Cd}\left(\mathrm{NO}_{3}\right)_{2} \cdot 4 \mathrm{H}_{2} \mathrm{O}, \mathrm{Pd}\left(\mathrm{NO}_{3}\right)_{2}, \mathrm{Al}\left(\mathrm{NO}_{3}\right)_{3} \cdot 9 \mathrm{H}_{2} \mathrm{O}$ and $\mathrm{AgNO}_{3}$. All the metal ion solutions for the study were prepared in distilled water. ${ }^{1} \mathrm{H}$ and ${ }^{13} \mathrm{C}$ NMR spectra were obtained by a JEOL EX-400 spectrometer with acetone- $d_{6}$ as solvent and tetramethylsilane as the internal reference. UV-Vis spectra were acquired through a Lambda 35 spectrophotometer (PerkinElmer) and fluorescence were recorded by a LS-55 spectrofluorophotometer (PerkinElmer).

Synthesis of the salicylidene Schiff base (TPySSB)

4'-Amine-2,2':6',2"'-terpyridines (0.324 g, $1 \mathrm{mmol})$ was put into a $100 \mathrm{~mL}$ round-bottom flask equipped with condenser, thermometer and magnetic stirrer. With the supplement of methanol $(40 \mathrm{~mL})$ to the flask, the reaction mixture was heated up to $80{ }^{\circ} \mathrm{C}$. The solution composed of $0.122 \mathrm{~g}(1 \mathrm{~mol})$ salicylaldehyde and $10 \mathrm{~mL}$ methanol was added subsequently. After $24 \mathrm{~h}$ reaction under reflux, the resulting solution was cooled to room temperature to give yellow powder, which was filtered, washed with methanol and dried under vacuum to obtain yellow powder product $(0.35 \mathrm{~g}$, yield: $82.4 \%)$. FTIR $(\mathrm{KBr}$, Figure S1, SI section) $v / \mathrm{cm}^{-1} 3410(\mathrm{O}-\mathrm{H}), 3054(\mathrm{C}-\mathrm{N})$, $1622(\mathrm{C}=\mathrm{N}), 1573(\mathrm{C}=\mathrm{C}), 1493$ and $1454(\mathrm{C}=\mathrm{N}), 1279$ (C-O); ${ }^{1} \mathrm{H}$ NMR (400 MHz, acetone- $d_{6}$, TMS, Figure S2, SI section) $\delta 13.18(\mathrm{~s},-\mathrm{OH}), 8.96(\mathrm{~s},-\mathrm{N}=\mathrm{CH}), 7.96(\mathrm{~d}$, $J 8 \mathrm{~Hz}, 2 \mathrm{H}), 7.86(\mathrm{~d}, J 8 \mathrm{~Hz}, 2 \mathrm{H}), 7.58(\mathrm{~d}, J 8 \mathrm{~Hz}, 2 \mathrm{H})$, 7.49 (d, $J 8 \mathrm{~Hz}, 2 \mathrm{H}), 7.46-7.31(\mathrm{~m}, 8 \mathrm{H}), 6.94(\mathrm{~d}, J 8 \mathrm{~Hz}$, $2 \mathrm{H}) ;{ }^{13} \mathrm{C}$ NMR (100 MHz, acetone- $d_{6}$, TMS, Figure S3, SI section) $\delta 164.41,162.24,148.79,137.90,134.18,133.86$, 129.79, 128.87, 127.35, 126.30, 122.81, 120.46, 120.02, $117.78,100.62$; HRMS $m / z$, calcd. for $\mathrm{C}_{28} \mathrm{H}_{21} \mathrm{~N}_{4} \mathrm{O}[\mathrm{M}+\mathrm{H}]^{+}$: 429.1716, found: 429.0874 .

\section{Synthesis of the Schiff base (TPySB)}

The Schiff base (TPySB) was also synthesized by the same method. 0.37 g, yield: 89.8\%; FTIR (KBr, Figure S1, SI section) $v / \mathrm{cm}^{-1} 3059$ and $3026(\mathrm{C}-\mathrm{N}), 1620(\mathrm{C}=\mathrm{N})$, $1517(\mathrm{C}=\mathrm{C}), 1446(\mathrm{C}=\mathrm{N})$; ${ }^{1} \mathrm{H}$ NMR $\left(400 \mathrm{MHz}\right.$, acetone- $d_{6}$, TMS, Figure S4, SI section) $\delta 8.56(\mathrm{~s},-\mathrm{N}=\mathrm{CH}), 8.02-$ $6.73(\mathrm{~m}, 19 \mathrm{H})$; HRMS $m / z$, calcd. for $\mathrm{C}_{28} \mathrm{H}_{21} \mathrm{~N}_{4}[\mathrm{M}+\mathrm{H}]^{+}$: 413.1767, found: 413.1058 .

\section{Supplementary Information}

Supplementary information is available free of charge at http://jbcs.sbq.org.br as PDF file.

\section{Acknowledgments}

The authors are grateful for the research support from the National Natural Science Foundation of China (No. 51808414, 21908169), China Postdoctoral Science Foundation (No. 2017M612520), National Science Foundation of Hubei Province of China (No. 2016CFB264, 2018CFB108) and the Program of Hubei Provincial Department of Education, China (No. Q20171507).

\section{Author Contributions}

Jiacheng Xu was responsible for the data curation; Hui $\mathrm{Li}$ for the resources and writing original draft; Liangwei $\mathrm{Li}$ for the data curation; Jianzhi Wang for the writing review and editing; Feng Wang for the resources; Luying He for the writing review and editing.

\section{References}

1. Berthon, G.; Coord. Chem. Rev. 1996, 149, 241.

2. Liang, C.; Bu, W.; Li, C.; Men, G.; Deng, M.; Jiangyao, Y.; Sun, H.; Jiang, S.; Dalton Trans. 2015, 44, 11352; Li, H.; Wang, J.; Zhang, S.; Gong, C.; Wang, F.; RSC Adv. 2018, 8, 31889; Sun, J.; Ye, B.; Xia, G.; Wang, H.; Sens. Actuators, B 2017, 249, 386; Shu, Y. L.; Zhang, D. B.; Jin, Y. W.; Rui, M. L.; Zheng, C. H.; Shou, Z. P.; Sens. Actuators, B 2017, 245, 263.

3. Li, J.; Hu, Q.; Yu, X.; Zeng, Y.; Cao, C.; Liu, X.; Guo, J.; Pan, Z.; J. Fluoresc. 2011, 21, 2005; Piyanuch, P.; Watpathomsub, S.; Lee, V. S.; Nienaber, H. A.; Wanichacheva, N.; Sens. Actuators, B 2016, 224, 201; Li, J.; Zeng, Y.; Hu, Q.; Yu, X.; Guo, J.; Pan, Z.; Dalton Trans. 2012, 41, 3623; Sinha, S.; Chowdhury, B.; Ghosh, P.; Inorg. Chem. 2016, 55, 9212.

4. Hu, S.; Song, J.; Wu, G.; Cheng, C.; Gao, Q.; Spectrochim. Acta, Part A 2015, 136, 1188.

5. In, B.; Hwang, G. W.; Lee, K.; Bioorg. Med. Chem. Lett. 2016, $26,4477$.

6. Wang, H.; Wang, B.; Shi, Z.; Tang, X.; Dou, W.; Han, Q.; Zhang, Y.; Liu, W.; Biosens. Bioelectron. 2015, 65, 91.

7. Ding, W.; Cao, W.; Zheng, X.; Ding, W.; Qiao, J.; Jin, L.; Dalton Trans. 2014, 43, 6429.

8. Bian, G.; Guo, Y.; Lv, X.; Zhang, C.; J. Mol. Struct. 2016, 1111, 1.

9. Zhang, S. J.; Li, H.; Gong, C. L.; Wang, J. Z.; Wu, Z. Y.; Wang, F.; Synth. Met. 2016, 217, 37; Li, H.; Zhang, S.; Gong, C.; Wang, J.; Wang, F.; J. Fluoresc. 2016, 26, 1555. 
10. Chao, D.; Ni, S.; Mu, W.; Chem. Lett. 2016, 45, 27; Li, L.; Du, L.-t.; Sun, J.; Yan, C.-g.; Chem. Res. Chin. Univ. 2013, 29, 874; Hu, Q.; Tan, Y.; Liu, M.; Yu, J.; Cui, Y.; Yang, Y.; Dyes Pigm. 2014, 107, 45.

11. Sun, S.; Wang, C.; Han, S.; Jiao, T.; Wang, R.; Yin, J.; Li, Q.; Wang, Y.; Geng, L.; Yu, X.; Colloids Surf., A 2019, 564, 1.

12. Abdalrahman, M. A.; Abebe, F.; Briggs, J.; Kassel, W. S.; Burdette, S. C.; Seitz, W. R.; Planalp, R. P.; J. Coord. Chem. 2017, 70, 1123; Jing, S.; Zheng, C.; Pu, S.; Fan, C.; Liu, G.; Dyes Pigm. 2014, 107, 38; Li, P.; Xiao, H.; Tang, B.; Chin. J. Chem. 2012, 30, 1992; Bhaumik, C.; Das, S.; Maity, D.; Baitalik, S.; Dalton Trans. 2011, 40, 11795.

13. Fang, B.; Liang, Y.; Chen, F.; Talanta 2014, 119, 601; Gou, C.; Wu, H.; Jiang, S.; Yi, C.; Luo, J.; Liu, X.; Chem. Lett. 2011, 40, 1082.

14. Wu, J.-S.; Liu, W.-M.; Zhuang, X.-Q.; Wang, F.; Wang, P.-F.; Tao, S.-L.; Zhang, X.-H.; Wu, S.-K.; Lee, S.-T.; Org. Lett. 2007, 9, 33 .

15. Maity, D.; Govindaraju, T.; Eur. J. Inorg. Chem. 2011, 2011, 5479 .
16. Chalmardi, G. B.; Tajbakhsh, M.; Hasa, N.; Bekhradnia, A.; Tetrahedron 2018, 74, 2251.

17. Wu, J.-S.; Zhou, J.-H.; Wang, P.-F.; Zhang, X.-H.; Wu, S.-K.; Org. Lett. 2005, 7, 2133.

18. Kopchuk, D. S.; Prokhorov, A. M.; Slepukhin, P. A.; Kozhevnikov, D. N.; Tetrahedron Lett. 2012, 53, 6265.

19. Li, Z.; Wu, S.; J. Fluoresc. 1997, 7, 237.

20. Xu, H.; Tao, X.; Li, Y.; Shen, Y.; Wei, Y.; Spectrochim. Acta, Part A 2012, 91, 375.

21. Tang, Y.; Cui, S.; Pu, S.; J. Fluoresc. 2016, 26, 1421.

22. Zhang, C.; Pu, S.; Sun, Z.; Fan, C.; Liu, G.; J. Phys. Chem. B 2015, 119, 4673.

23. Saini, A. K.; Sharma, V.; Mathur, P.; Shaikh, M. M.; Sci. Rep. 2016, 6, 34807.

24. Li, H.; Zhang, S.; Gong, C.; Li, Y.; Liang, Y.; Qi, Z.; Chen, S.; Analyst 2013, 138, 7090.

Submitted: October 11, 2019

Published online: April 7, 2020 